\title{
Analisis Pengaruh Bentuk Slidding Roller Terhadap Torsi dan Daya Kendaraan Berbasis Continously Variable Transmission
}

\author{
Dedik Ananta Wijaya*, K Rihendra Dantes, I N Pasek Nugraha \\ Progam Studi Pendidikan Teknik Mesin Fakultas Teknik dan Kejuruan, Universitas \\ Pendidikan Ganesha, Singaraja, Indonesia \\ *Penulis korespondensi: anantamd@yahoo.com
}

Histori artikel: diserahkan 10 Januari 2021, direviu 02 Februari 2021, direvisi 17 Maret 2021

\begin{abstract}
This study aims to determine the ratio of power and torque on an automatic motorbike using two different rollers, namely a cylindrical roller with a sliding roller with a weight of 12 grams each. The method used in this research is the experimental method. The testing and retrieval process carried out at the Gede Widi Motor workshop, and data collection was carried out five repetitions for each variation. After testing, there are differences in torque and power on the cylinder roller with roller sliding. The cylinder roller reaches the highest torque of $7.6 \mathrm{Nm}$ at $4000 \mathrm{rpm}$. The highest power is $7.46 \mathrm{Hp}$ at Rpm 7000, while in roller sliding, the highest torque is $11.82 \mathrm{Nm}$ at 4000 rpm and the highest power $7.56 \mathrm{HP}$ at $7000 \mathrm{rpm}$.
\end{abstract}

Keywords: torque, power, cylinder roller, slidding roller

DOI : https://doi.org/10.18196/jqt.v2i2.10788

WEB : https://journal.umy.ac.id/index.php/qt/article/view/10788

\section{PENDAHULUAN}

Perkembangan teknologi dan ilmu pengetahuan yang sangat pesat menuntut industri otomotif kususnya untuk menciptakan inovasi-inovasi yang dapat membantu atau mempermudah konsumen dalam penggunaanya. Dilihat seperti saat ini penggunaan kendaraan sudah semakin meningkat dan menjadi salah satu kebutuhan masyarakat dalam melakukan aktivitas dalam kehidupan sehari-hari. Oleh sebab untuk memenuhi kebutuhan konsumen setiap produsen otomotif dituntut untuk menciptakan inovasi-inovasi dalam teknologi kendaraan.

Sepeda motor saat ini diproduksi tidak hanya satu jenis sepeda motor, kendaraan sepeda motor terbagi menjadi dua jenis berdasarkan sistem penggeraknya yaitu, Sepeda motor penggerak manual dan sepeda motor penggerak otomatis atau Continously Variable Transmission (CVT). Subagia et al. (2009) mengatakan sistem transmisi otomatis ini banyak digunakan pada sepeda motor jenis scooter dan dikenal dengan nama Continously Variable Transmission yang merupakan sistem transmisi baru tanpa gigi. Saat ini sepeda motor penggerak otomatis atau Continously Variable
Transmission lebih diminati karena memiliki beberapa kelebihan, salah satunya adalah lebih praktis dalam pemakaian dibandingkan dengan sepeda motor yang bertransmisi manual. Pengendara tidak perlu lagi secara manual merubah transmisi kecepatan kendaraanya, tetapi secara otomatis berubah sesuai dengan putaran mesin, sehingga sangat cocok digunakan di daerah perkotaan yang sering dihadang kemacetan. Perpindahan transmisi sangat lembut dan tidak terjadi hentakan seperti pada sepeda motor konvensional sehingga sangat nyaman dikendarai. Selain memiliki kelebihan, transmisi ototmatis Continously Variable Transmission juga memiliki kekurangan yaitu, akselerasi kurang baik ketika berjalan jauh, sangat boros bahan bakar, kecepatnnya yang dihasilkan tidak setinggi kendaraan bertransmisi manual. Namun setiap produsen otomotif berusaha menciptakan produk-produk baru untuk menutupi kekurangan dari produk sebelumnya dan untuk bersaingan dalam pasar otomotif, seiring waktu muncul kendaraan-kendaraan jenis baru dengan fitur-fitur baru sehingga konsumen merasa kendaraan pendahulu yang sudah digunakan memiliki performa yang sudah menurun sehingga banyak konsumen ingin mengganti kendaraannya dengan yang baru. Namun masih 
banyak konsumen yang masih tetap memakai kendaraan yang lama karena berbagai alasan, misalnya harga kendaraan yang baru cenderung mahal. Maka dari itu disini peneliti ingin meningkatkan performa kendaraan berbasis Continously Variable Transmission hanya dengan mengganti sebuah komponen dengan harapan bisa meningkatkan performa kendaraan. Adapun kendaraan yang di pakai dalam penelitian ini adalah Honda Vario CW 110 cc tahun 2010, alasan peneliti memilih Honda Vario CW 110 cc 2010 karena umur kendaraan yang sudah lumayan tua tetapi jumlah populasi kendaraan tersebut masih banyak digunakan oleh konsumen otomotif sehingga peneliti berharap bisa meningkatkan performa kendaraan yang sudah berumur dengan memodifikasi pada bagian transmisi.

Rochadi (2009) menyatakan "Roller adalah bantalan keseimbangan gaya berat yang berguna untuk menekan dinding dalam puli primer sewaktu terjadi putaran tinggi ". Menurut Han (2010) terdapat berbagai macam varian dan berat roller sesuai dengan kondisi pemakaiannya

Pada transmisi otomatis terdapat komponen yang bernama roller yang berfungsi merubah besar kecilnya diameter pulley berdasarkan putaran dari mesin kendaraan. Berat roller sentrifugal sangat berpengaruh terhadap kemampuan kendaraan untuk berakselerasi dan menghasilkan kinerja traksi yang paling baik, karena pada kecepatan rendah dibutuhkan kemampuan akselerasi yang besar. Kinerja traksi kendaraan didefinisikan sebagai kemampuan kendaraan untuk dipercepat, dan mengatasi hambatan-hambatan yang terjadi, diantaranya hambatan rolling ban (rolling resistance), hambatan aerodinamis, dan hambatan tanjakan.

Kemampuan kendaraan tersebut sangat dipengaruhi oleh kemampuan mesin kendaraan dan pemilihan tingkat serta rasio transmisi. Selain berat roller, bentuk roller juga bepengaruh terhadap kemampuan kendaraan karena pada transmisi otomatis (CVT) pada umumnya menggunakan roller berbentuk silinder namun pada putaran atas roller silinder tidak sepenuhnya berputar sehingga terjadi gesekan yang efeknya adalah lebih cepatnya roller menjadi aus serta performa kendaraan di kecepatan tinggi menjadi lebih cepat turun. Jika hal ini terjadi, maka pengendara harus memainkan gas sedikit-sedikit untuk menjaga kestabilan kecepatan. Namun perlakuan membuka tutup gas ini menjadi salah satu penyebab skuter matic menjadi boros. Selain roller komponen-komponen lain pada CVT juga bisa mempengaruhi torsi dan daya kendaraan seperti $v$-belt, $v$-belt berfungsi untuk meneruskan putaran pulley bagian depan (engine) menuju pulley belakang (roda), $v$-belt terbuat dari karet dan mempunyai penampang trapesium dipergunakan sebagai inti sabuk untuk membawa tarikan yang besar. Selain melakukan modifikasi pada roller, pulley, maupun komponen lainnya perawatan pada $v$ belt juga harus rutin sehingga tenaga yang diteruskan dari driver pulley ke driven pulley dapat diteruskan secara maksimal.

Beberapa peneliti mengesplorasi tentang CVT. Salam et al. (2016) menyatakan bahwa roller 14 gram memiliki daya efektif yang paling besar dibandingkan dengan roller 10 gram dan 13 gram pada putaran $2000-4000 \mathrm{rpm}$.

Susena et al. (2016), melakukan Pengukuran menggunakan tachometer digital dan perhitungan, sudut primary pulley $13,5^{\circ}$ dengan variasi berat roller 10/12 gram mendapatkan rpm tertinggi sebesar $5.396 \mathrm{rpm}$ dan torque tertinggi sebesar 4,583 lb-ft pada roller 12 gram. Sedangkan sudut primary pulley standart $14^{\circ}$ dengan variasi berat roller 11/12 gram mendapatkan rpm tertinggi sebesar $4.673 \mathrm{rpm}$ dan Torque tertinggi sebesar 4,637 pada roller 12 gram.

\section{METODE}

Metode yang digunakan dalam penelitian ini adalah metode eksperimen. Menurut Sugiyono (2012) Metode penelitian eksperimen adalah penelitian yang digunakan untuk mencari pengaruh perlakuan tertentu terhadap yang lain dalam kondisi yang terkendali. Pada penelitian ini, penulis lebih memilih untuk menggunakan metode eksperimen. Langkah-langkah yang perlu diperhatikan dalam penelitian eksperimen diawali dengan menentukan masalah yang akan dijadikan topik penelitian, selanjutknya mencari sampel dalam populasi yang telah ditentukan, lalu mencari refrensi sebagai dasar teoritis untuk menyusun hipotesis, kemudian mengelompokkan variabel kontrol dan variabel eksperimen serta menyusun instrument, 
selanjutnya dilakukan tindakan atau treatment pada salah satu variabel atau kedua variabel dengan tindakan yang berbeda, setelah selesai tindakan data yang didapat kemudian dianalisa sesuai atau tidak dengan hipotesis yang disusun. Dari masing-masing variasi dilakukan 5 kali pengujian, setelah mendapatkan hasil dari pengujian masing-masing variasi tersebut, selanjutnya data hasil uji dimasukkan kedalam tabel. Torsi adalah gaya tekan putar pada bagian yang berputar (Jama, 2008). Kemudian data tersebut akan dianalisis dengan menggunakan statistik deskriptif melalui gambar grafik dan tabel dengan menggunakan media software microsoft excel sehingga data hasil atau nilai yang di dapat lebih mudah untuk dipahami dan dianalisis.

\section{HASIL DAN PEMBAHASAN}

Pada penelitian ini memperlihatkan hasil daya dan torsi pada penggunaan roller silinder dan roller slidding pada Honda Vario CW $110 \mathrm{cc}$.

\section{Hasil Pengujian Torsi}

Keterangan Tabel 1 menunjukkan perbedaan torsi pada sepeda motor menggunakan roller silinder dan roller slidding pada perbedaan rentang putaran mesin $1000 \mathrm{rpm}$.

TABEL 1. Data torsi dari putaran mesin 4000 rpm sampai 8000 rpm

\begin{tabular}{|c|c|c|}
\hline \multicolumn{3}{|c|}{ TORSI } \\
\hline $\begin{array}{c}\text { Putaran } \\
\text { Mesin }\end{array}$ & Roller Silinder & Roller Slidding \\
\hline \multirow{5}{*}{4000} & 5,81 & 10,37 \\
\hline & 5,73 & 13,13 \\
\hline & 8,78 & 8,78 \\
\hline & 10,37 & 11,99 \\
\hline & 8,12 & 14,86 \\
\hline rata rata & 7,76 & 11,82 \\
\hline \multirow{5}{*}{5000} & 6,64 & 9,88 \\
\hline & 7,01 & 13,47 \\
\hline & 9,68 & 9,68 \\
\hline & 9,7 & 9,76 \\
\hline & 9,43 & 13,06 \\
\hline rata rata & $\mathbf{8 , 5 0}$ & 11,17 \\
\hline \multirow{5}{*}{6000} & 6,33 & 8,63 \\
\hline & 6,87 & 11,47 \\
\hline & 8,34 & 8,34 \\
\hline & 8,25 & 8,32 \\
\hline & 8,38 & 10,98 \\
\hline rata rata & 7,64 & 9,55 \\
\hline \multirow{5}{*}{7000} & 5,72 & 7,69 \\
\hline & 6,42 & 9,71 \\
\hline & 7,4 & 7,38 \\
\hline & 7,33 & 7,23 \\
\hline & 7,14 & 9,6 \\
\hline rata rata & 6,80 & 8,32 \\
\hline
\end{tabular}


Wijaya, D.A. et al. / Quantum Teknika Vol. 2 No. 2 (ISSN: 2721-1932)

\begin{tabular}{llc}
\hline & 5,01 & 6,57 \\
\cline { 2 - 3 } 8000 & 5,38 & 8,42 \\
\cline { 2 - 3 } & 7,38 & 6,32 \\
\cline { 2 - 3 } & 6,32 & 6,15 \\
\cline { 2 - 3 } rata rata & 6,24 & 8,2 \\
\hline
\end{tabular}

TABEL 2. Data rata-rata dari torsi putaran mesin $4000 \mathrm{rpm}$ sampai $8000 \mathrm{rpm}$

\begin{tabular}{ccc}
\hline \multirow{2}{*}{$\begin{array}{c}\text { Putaran } \\
\text { Mesin }\end{array}$} & Roller Silinder & Torsi \\
\cline { 2 - 3 } & 7,76 & Roller Slidding \\
\hline 4000 & 8,5 & 11,82 \\
\hline 5000 & 7,64 & 11,17 \\
\hline 6000 & 6,8 & 9,55 \\
\hline 7000 & 6,7 & 8,32 \\
\hline 8000 & & 7,13 \\
\hline
\end{tabular}

Berikut adalah penjabaran data tabel rata-rata torsi di atas dalam bentuk grafik:

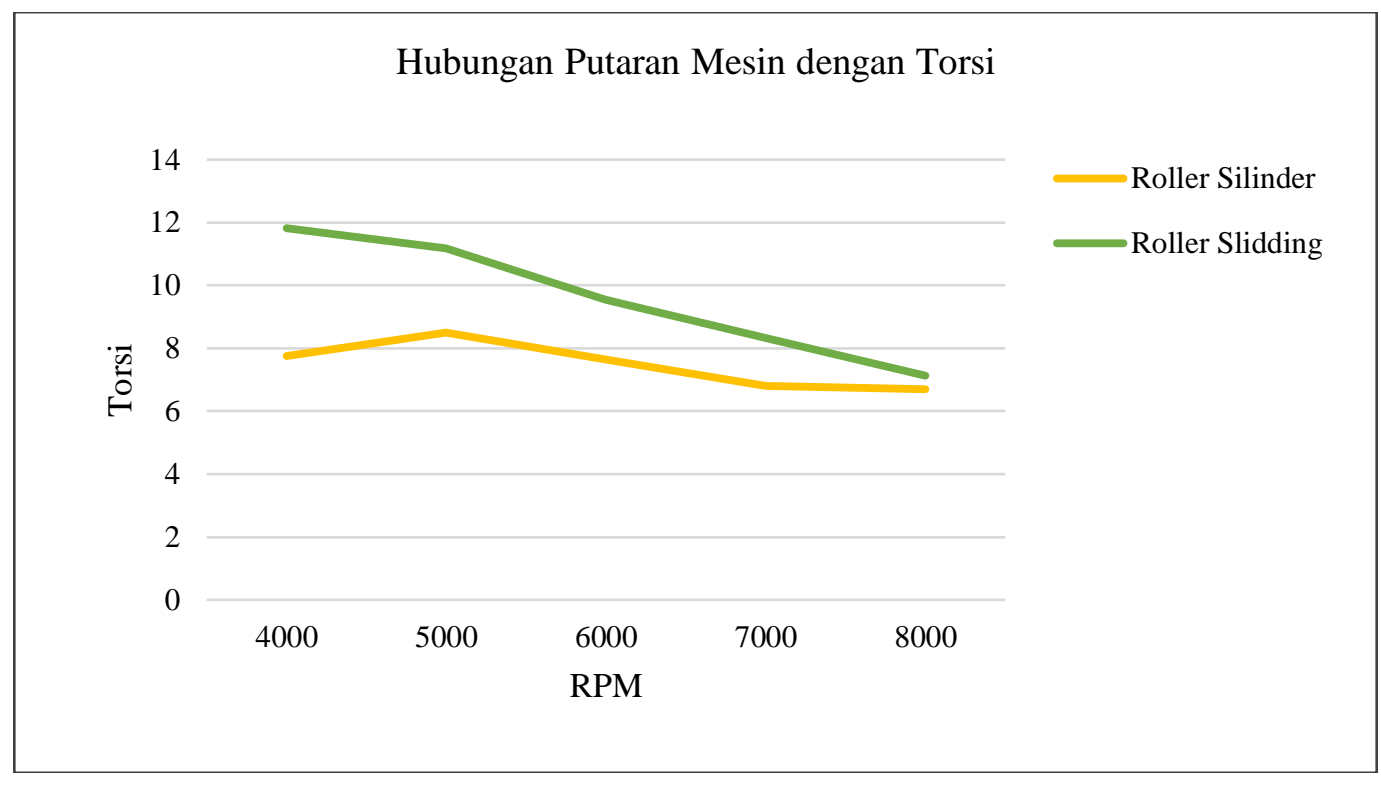

GAMBAR 1. Grafik Hubungan Rata-rata Torsi Dengan Putaran Mesin Dari 3000 Sampai 8000 rpm

Analisa hasil pengujian torsi yang dilakukan pada kendaraan Honda Vario cw $110 \mathrm{cc}$, pada analisa data deskriptif menggunakan skala lima teoritik menggunakan roller silinder berada pada kategori sedang dan roller slidding berada pada kategori rendah. Torsi yang dihasilkan kendaraan menggunakan roller silinder menghasilkan torsi tertinggi sebesar 8,5 N.m pada rpm 5000 namun pada roller slidding menghasilkan torsi tertinggi sebesar 11,82 N.m pada rpm 4000, selisih perbedaan antara roller silinder dengan roller slidding tersebut sebesar $39 \%$. Perbedaan tersebut dikarenakan roller memiliki memiliki bentuk yang berbeda roller silinder berbentuk lingkaran sedangkan roller slidding berbentuk menyerupai trapesium sehingga dapat mendorong speed governor secara maksimal. 
Wijaya, D.A. et al. /Quantum Teknika Vol. 2 No. 2 (ISSN: 2721-1932)

TABEL 3. Data daya dari putaran mesin $4000 \mathrm{rpm}$ sampai $8000 \mathrm{rpm}$

\begin{tabular}{|c|c|c|}
\hline \multicolumn{3}{|c|}{ Daya } \\
\hline $\begin{array}{l}\text { Putaran } \\
\text { mesin }\end{array}$ & Roller Silinder & Roller Slidding \\
\hline \multirow{5}{*}{4000} & 5,8 & 6,8 \\
\hline & 5,7 & 4,8 \\
\hline & 5,3 & 5,4 \\
\hline & 6,3 & 6,8 \\
\hline & 4,9 & 5,4 \\
\hline rata rata & 5,6 & 5,84 \\
\hline \multirow{5}{*}{5000} & 7,5 & 7,4 \\
\hline & 6,5 & 6,8 \\
\hline & 7,2 & 7,4 \\
\hline & 7 & 7,6 \\
\hline & 6 & 6,2 \\
\hline rata rata & 6,84 & 7,08 \\
\hline \multirow{5}{*}{6000} & 7,6 & 7,7 \\
\hline & 7,5 & 7,5 \\
\hline & 7,4 & 7,4 \\
\hline & 7,3 & 7,4 \\
\hline & 7,4 & 7,5 \\
\hline rata rata & 7,44 & 7,5 \\
\hline \multirow{5}{*}{7000} & 7,5 & 7,9 \\
\hline & 7,4 & 7,3 \\
\hline & 7,5 & 7,6 \\
\hline & 7,6 & 7,6 \\
\hline & 7,3 & 7,4 \\
\hline rata rata & 7,46 & 7,56 \\
\hline \multirow{5}{*}{8000} & 7,2 & 7,6 \\
\hline & 7 & 7,5 \\
\hline & 7,4 & 7,4 \\
\hline & 7,4 & 7,4 \\
\hline & 7,2 & 7,4 \\
\hline rata rata & 7,24 & 7,46 \\
\hline
\end{tabular}


Wijaya, D.A. et al. / Quantum Teknika Vol. 2 No. 2 (ISSN: 2721-1932)

TABEL 4. Data Rata-rata Dari Daya Putaran Mesin 4000 rpm Sampai 8000 rpm

\begin{tabular}{ccc}
\hline \multirow{2}{*}{$\begin{array}{c}\text { Putaran } \\
\text { Mesin }\end{array}$} & \multicolumn{3}{c}{ Daya } \\
\cline { 2 - 3 } & Roller Silinder & Roller Slidding \\
\hline 4000 & 5,6 & 5,84 \\
\hline 5000 & 6,84 & 7,08 \\
\hline 6000 & 7,44 & 7,5 \\
\hline 7000 & 7,46 & 7,56 \\
\hline 8000 & 7,24 & 7,46 \\
\hline
\end{tabular}

Berikut adalah penjabaran data tabel rata-rata daya di atas dalam bentuk grafik:

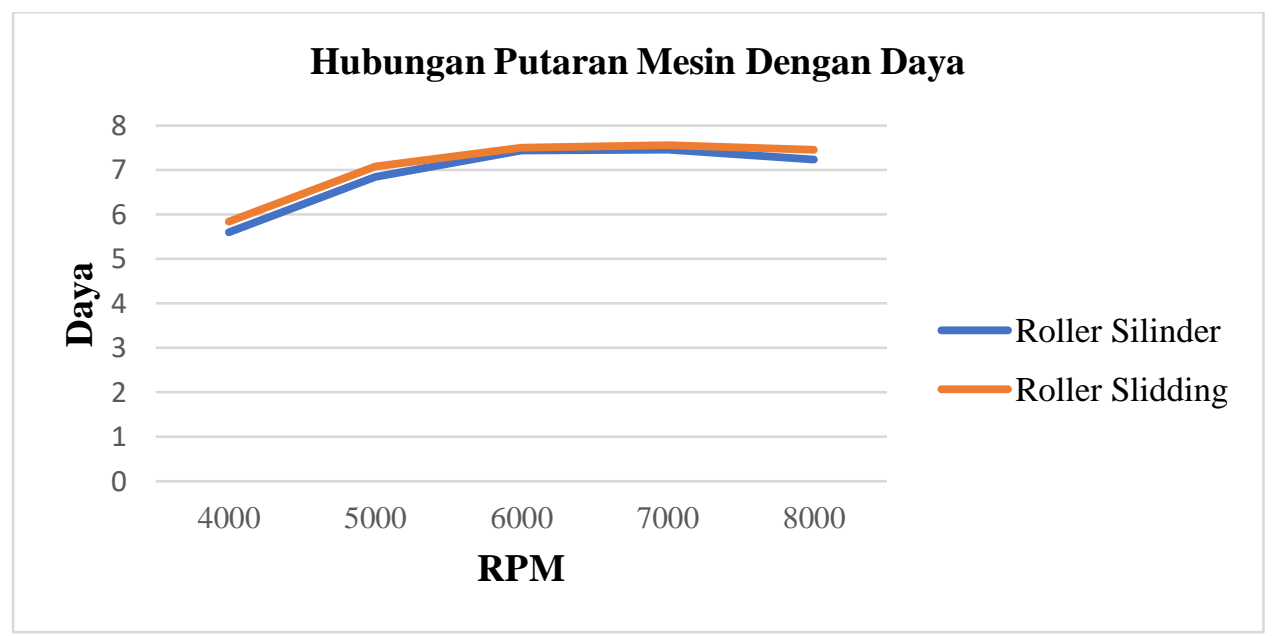

GAMBAR 2. Grafik Hubungan Rata-rata Torsi Dengan Putaran Mesin Dari 4000 Sampai 8000 rpm

\section{Hasil Pengujian Daya}

Dalam keterangan ini memperlihatkan perbedaan daya pada sepeda motor menggunakan roller silinder dengan roller slidding pada perbedaan rentang putaran mesin $1000 \mathrm{rpm}$ yang dipaparkan pada tabel berikut ini. Berikut adalah penjabaran data rata-rata daya dalam 5 kali pengujian pada masingmasing putaran mesin (rpm) dari tabel di atas. Analisa hasil pengujian daya yang dilakukan pada kendaraan Honda Vario cw $110 \mathrm{cc}$, pada analisa data deskriptif menggunakan skala lima teoritik menggunakan roller silinder berada pada kategori sangat tinggi dan roller slidding berada pada kategori sangat tinggi. Daya yang dihasilkan kendaraan menggunakan roller silinder menghasilkan daya tertinggi sebesar 7,46 Hp pada rpm 7000 sedangkan pada roller slidding menghasilkan daya tertinggi sebesar 7,56 Hp pada rpm 7000, selisih perbedaan antara roller silinder dengan roller slidding tersebut sebesar $1,3 \%$.

\section{KESIMPULAN}

1. Pengaruh bentuk roller slidding terhadap torsi kendaraan, dapat dilihat dari hasil torsi tertinggi dari roller slidding 11,82 N.m pada rpm 4000 lebih tinggi dibandingkan dengan torsi tertinggi yang dihasilkan roller silinder sebesar 8,5 N.m pada rpm 5000. Terjadi peningkatan torsi kendaraan ketika menggunakan roller slidding sebesar $39 \%$.

2. Pengaruh bentuk roller slidding terhadap torsi kendaraan, dapat dilihat dari hasil daya tertinggi roller slidding didapatkan 7,56 Hp pada rpm 7000 lebih tinggi dibandingkan dengan daya yang dihasilkan roller silinder sebesar 7,46 Hp pada rpm 7000. Peningkatan daya kendaraan sebesar 1,3\%, namun nilai rata-rata yang dihasilkan 
masing-masing roller tidak mencapai daya maksimal standar kendaraan

\section{DAFTAR PUSTAKA}

Jama, J., 2008. Teknik sepeda motor jilid 2 untuk SMK. Jakarta: Departemen Pendidikan Nasional.

Rochadi, 2009. Roller adalah bantalan keseimbangan gaya berat yang berguna untuk menekan dinding dalam puli primer

Rudi, Salam. 2016. Pengaruh Penggunaan Variasi Berat Roller Pada Sistem CVT (Continuously Variable Transmission) Terhadap Performa Sepeda Motor Beat $110 \mathrm{cc}$

Subagia, A., \& Amika, A., 2009. Sistem Transmisi Otomatis Pada Sepeda Motor Jenis Scooter Dikenal Dengan Nama CVT (Continously Variable Transmission)

Sugiyono. 2012. Metode Penelitian Pendidikan (Pendekatan Kuantitatif, Kualitatif, dan $\mathrm{R} \& \mathrm{D})$

Susena, I, G, T, A., Wigraha, N.A., \& Dantes, K, R., 2016. Pengaruh Sudut Primary Pulley Dan Variasi Berat Roller Terhadap Torque Dan Rpm Pada Motor Ganesha Electric Vehicles 1.0 Base Continous Variable Transmision (CVT). 1-9. http// 10.23887/jjtm.v5i1.9234 